\title{
STUDIES ON FAZADINIUM BROMIDE (AH 8165): A NEW NON-DEPOLARIZING NEUROMUSCULAR BLOCKING AGENT
}

\author{
R. Hughes, J.P. Payne, and N. SugaI
}

\section{INTRODUCTION}

Preliminary RePORTS on the neuromuscular blocking action of fazadinium ( $\mathrm{AH}$ 8165 ) demonstrated that it is a non-depolarizing agent, that its onset of action is rapid and that its duration is short in cats and dogs but longer in monkeys. ${ }^{1}$ In man, its duration of action was longer than expected and resembled that in monkeys; persistence of action in man was comparable with that of pancuronium. ${ }^{2}$ In cats, Marshall ${ }^{3}$ showed that ganglionic blockade was also produced by fazadinium but only with doses greater than those required to cause neuromuscular paralysis. Vagal blockade was caused, however, by doses less than those required for neuromuscular paralysis and it seems likely that such atropinic effects may lead to undesirable tachycardia in man. ${ }^{4}$ Indeed, it has already been reported that heart rate and cardiac output increase significantly after fazadinium in man but that arterial blood pressure remains steady. ${ }^{5}$

The studies reported here were carried out in anaesthetized cats, monkeys and man to investigate further the neuromuscular, cardiovascular and autonomic effects of fazadinium.

\section{Methods}

Experimental animals. Four cats weighing between 2.8 and $4.8 \mathrm{~kg}$ were studied after anaesthesia was induced with $4-8$ per cent halothane and maintained with chloralose (60 to $80 \mathrm{mg} / \mathrm{kg}$ iv) after cannulation of a jugular vein as described previously. ${ }^{4.8}$ The trachea was cannulated to allow artificial ventilation and to record the respiratory pattern. The carotid artery was cannulated to measure the blood pressure and the cannula inserted in the jugular vein allowed the administration of drugs. Neuromuscular block was assessed by measuring the response of the gastrocnemius muscle to stimulation of the sciatic nerve with rectangular pulses of supramaximal voltage and duration at a frequency of $0.1 \mathrm{~Hz}$. Effects on autonomic mechanisms were also investigated; parasympathetic activity was studied by measuring the bradycardia which ensued when 10-second bursts of periodic stimulation were applied to the cardiac end of the cut right cervical vagus nerve and sympathetic activity by recording the contractions of the nictitating membrane when the central end of the cut right preganglionic cervical sympathetic nerve was stimulated for 60 seconds at supramaximal voltage. Atropinic effects were confirmed by inducing bradycardia with metacholine $(100 \mathrm{mg})$ given intravenously.

Research Department of Anaesthetics, Royal College of Surgeons of England, Lincoln's Inn Fields, London WC2A 3PN; St. Peter's Hospital, London WC2; and Department of Pharmacology, The Wellcome Research Laboratories, Beckenham, Kent. 
Four rhesus monkeys of either sex, weighing between 3.4 and $3.6 \mathrm{~kg}$, were anaesthetized with thiopentone $(25 \mathrm{mg} / \mathrm{kg}$ iv $)$. Anaesthesia was maintained with nitrous oxide and oxygen supplemented by intravenous thiopentone ( 5 to $12 \mathrm{mg}$ ) as required. The methods of study were similar to those described for cats, but effects on sympathetic mechanisms were investigated by measuring the vasopressor response to carotid occlusion for 30 seconds.

Man. Studies were carried out after informed consent had been obtained in nine male patients about to undergo urological surgery. No premedication was given and anaesthesia was induced with halothane, nitrous oxide and oxygen. Endotracheal intubation was carried out without the use of a neuromuscular blocking agent. The halothane was then discontinued and anaesthesia maintained with nitrous oxide and oxygen supplemented by intravenous meperidine ( 100 to $200 \mathrm{mg}$ ) and diazepam (10 to $20 \mathrm{mg}$ ) in divided doses over two hours. Simultaneous measurements of tetanic and single twitch contractions of the adductor pollicis muscles were performed as described previously. ${ }^{6}$ The right ulnar nerve was stimulated tetanically at $50 \mathrm{~Hz}$ for one second every 12 seconds and the left with single square-wave pulses of 200 microsecond duration every 12 seconds. The blood pressure was measured directly from a polyethylene catheter inserted into the left radial artery at the wrist and the heart rate was recorded from the electrocardiogram. Fazadinium was given intravenously in divided doses of 0.1 or $0.2 \mathrm{mg} / \mathrm{kg}$ to three patients to obtain dose-response curves and by a single injection of $0.4 \mathrm{mg} / \mathrm{kg}$ to six patients to measure its course of action. The temperature of each hand was monitored with a surface probe; any difference was within one degree centigrade. Arterial blood was sampled from the radial artery for analysis of blood gases which were maintained within normal limits by assisted or controlled ventilation.

In six patients the tetanic-tension ratios and tetanic transmissions were determined by an Elliott 903 digital computer from on-line real-time data (See Figure 1). The tetanic-tension ratio, which is defined as the percentage magnitude of the tetanic contractions at the end of the one-second tetanus compared with the initial magnitude, reflects the degree of fade produced during neuromuscular block. Tetanic transmission was determined as the percentage of the initial peak tetanic height compared with the control peak height before drug treatment (Figure 1).

\section{Results}

Experimental animals. Intravenous doses of $2 \mathrm{mg} / \mathrm{kg}$ fazadinium bromide were required for complete neuromuscular blockade of the single-twitch response of the gastrocnemius muscle in 4 anaesthetized cats. The onset of action was about 1 minute and a mean of 15 minutes was required for full recovery. The dose-response relationships showed that vagal blockade occurred at doses below those required for neuromuscular paralysis (Figure 2). This vagal block was atropinic in nature since the cholinergic receptors in the heart were blocked, as demonstrated by the abolition of metacholine-induced bradycardia. Slight sympathetic blockade occurred with supramaximal doses as witnessed by some hypotension and slight bradycardia (Figure 2). These findings are to be published in detail elsewhere. ${ }^{8}$

In four rhesus monkeys, fazadinium was found to be about four times more 


\section{TETANIC CONTRACTION}

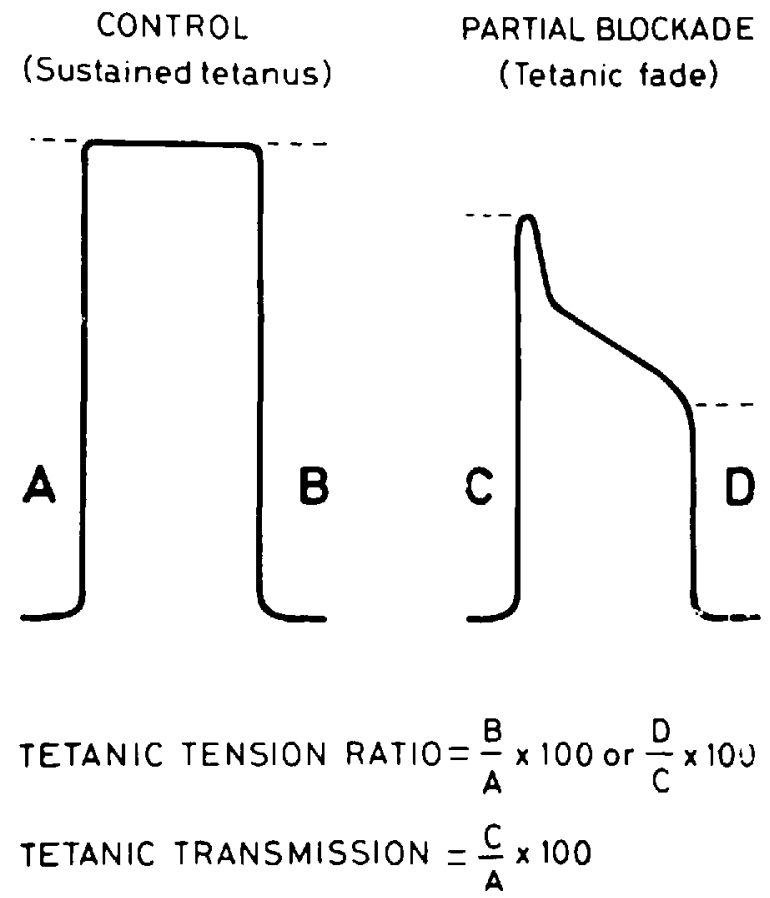

Figure 1. Diagram showing control tetanic contraction, tetanic fade and calculation of tetanic tension ratio and tetanic transmission.

potent than in cats, since a dose of $0.5 \mathrm{mg} / \mathrm{kg}$ intravenously was sufficient for complete paralysis (Figure 3 ). Its course of action was also considerably longer in the primate, 1.5 to 5 minutes being required for the onset of paralysis and a mean of 36 minutes for full recovery. Some sympathetic blockade and hypotension occurred with supramaximal doses (Figure 3); the dose-response curve for vagal blockade was similar to that seen in the cats (Figure 2).

Man. The dose-response curves obtained from the results in three patients (Figure 4) suggest that the potency of fazadinium in man corresponds more closely to that in cats rather than to that in monkeys. When given in increments of 0.1 or $0.2 \mathrm{mg} / \mathrm{kg}$ a total intravenous dose greater than $0.9 \mathrm{mg} / \mathrm{kg}$ was required for complete paralysis of the single-twitch response. As with other non-depolarizing neuromuscular blocking agents, the tetanic contractions of the muscles were more sensitive than the single twitches to the effects of fazadinium. Although changes in mean arterial blood pressure were minimal, the heart rate was progressively increased with increasing dosage and probably reflected the onset of vagal blockade similar to that observed in cats and monkeys.

In those six patients who received single doses of fazadinium $(0.4 \mathrm{mg} / \mathrm{kg}$ iv $)$, the inset of complete blockade of the tetanic contraction occurred within two minutes but recovery was slow and required a mean of 48 seconds for completion (Figure 


\section{Percent Inhibition} AH 8165
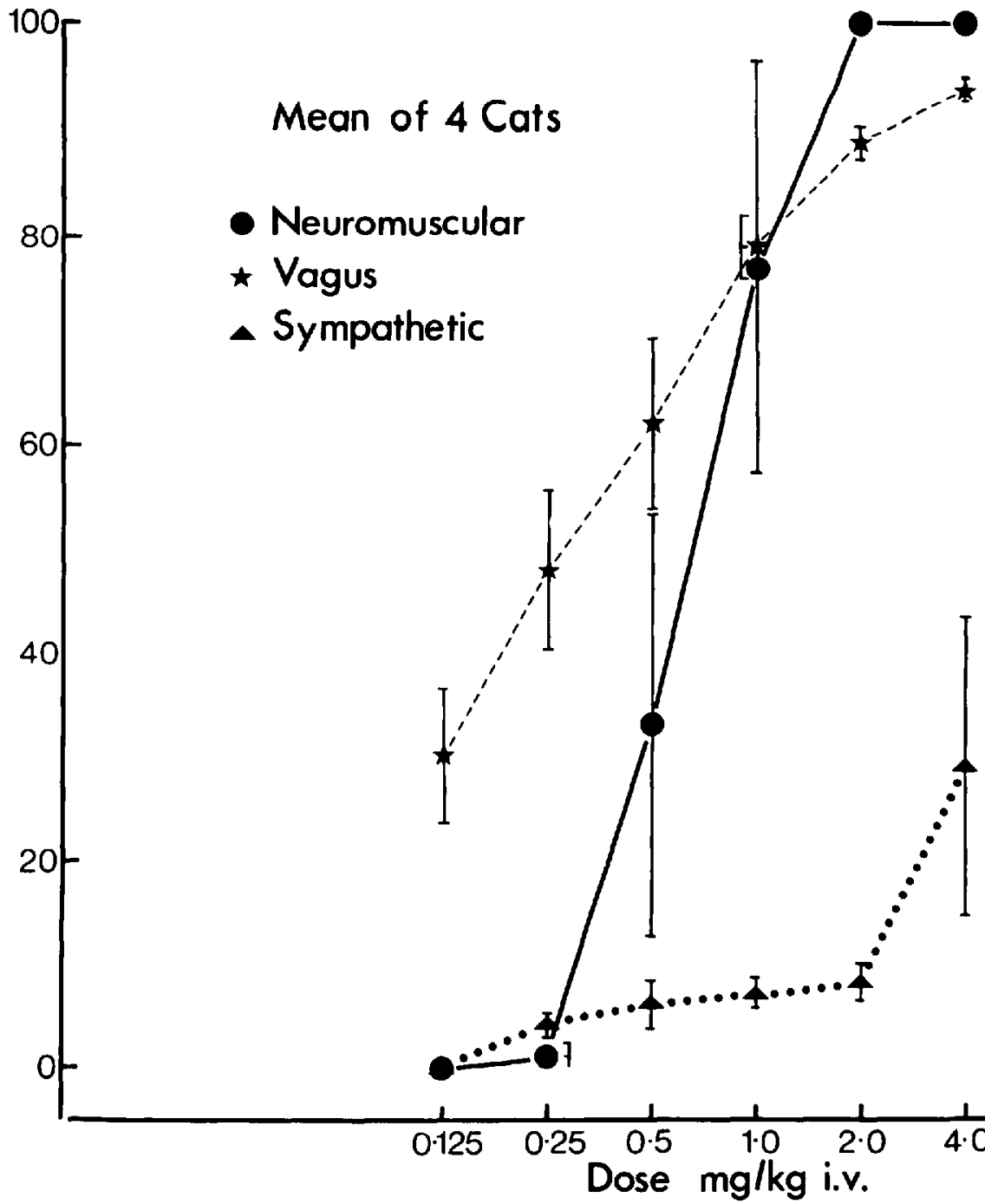

Figure 2. Dose response curves showing blockade of neuromuscular and autonomic mechanisms by fazadinium bromide ( $\mathrm{AH} 8165$ ) given intravenously to four cats anaesthetized with chloralose (each point represents the mean of 4 observations).

- - Percentage inhibition of the twitch response of the gastrocnemius muscle to indirect stimulation at $0.1 \mathrm{~Hz}$.

-...- Percentage inhibition of the bradycardia response to vagal stimulation at $10-20 \mathrm{~Hz}$ for $10 \mathrm{~s}$.

$\Delta$........ Percentage inhibition of the response of the nictitating membrane to sympathetic nerve stimulation at $10-20 \mathrm{~Hz}$ for $60 \mathrm{~s}$.

Vertical lines indicate standard errors.

Impairment of the vagally induced bradycardia occurred at dose-levels below those required to cause neuromuscular paralysis. The contractions of the nictitating membrane were slightly reduced by supramaximal paralysing doses. 


\section{AH 8165}

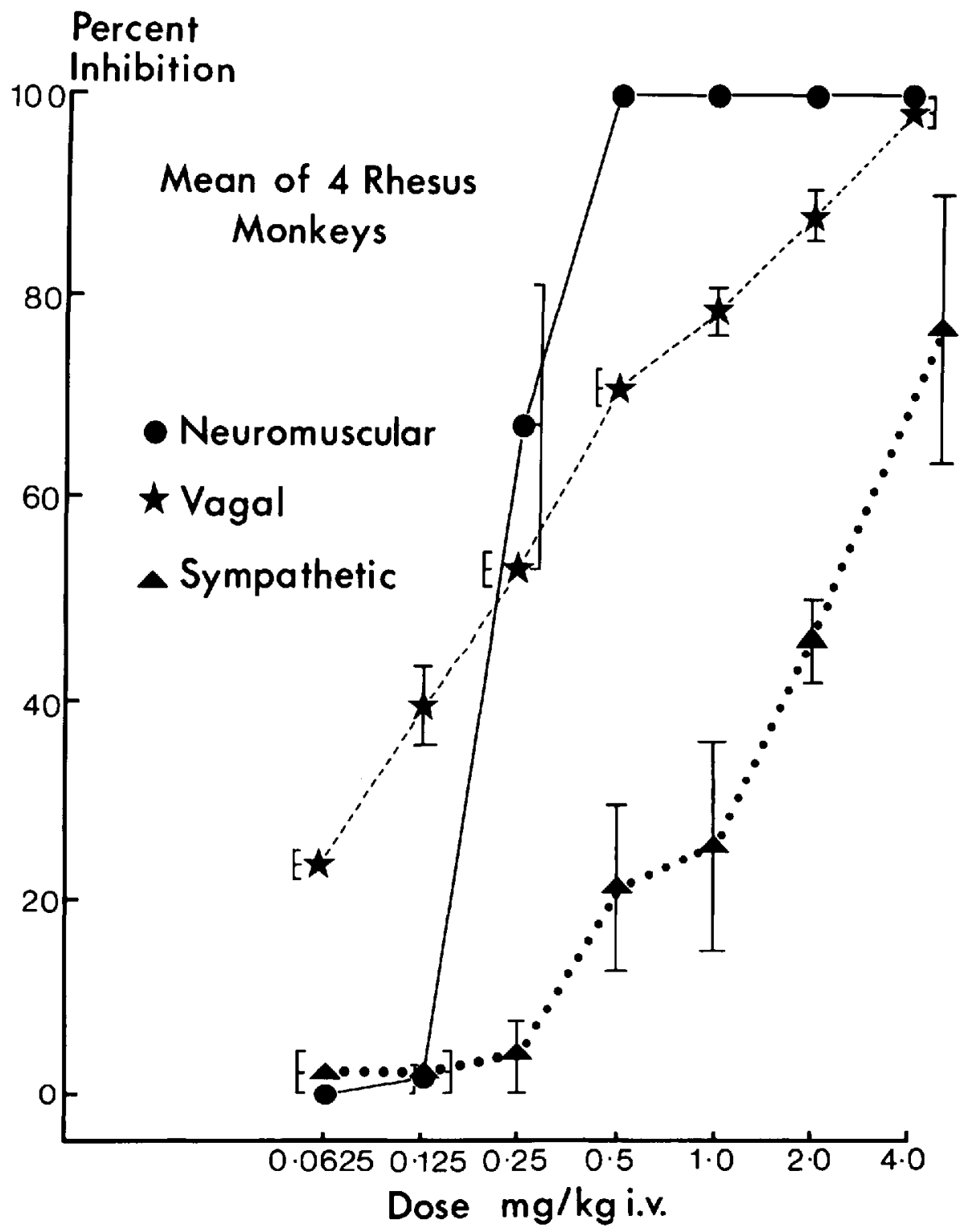

Figure 3. Dose response curves showing blockade of neuromuscular and vagal mechanisms by fazadinium bromide ( $\mathrm{AH} 8165$ ) given intravenously to four rhesus monkeys anaesthetized with chloralose.

Percentage inhibition of the twitch responses of the gastrocnemius muscle to indirect stimulation at $0.1 \mathrm{~Hz}$

- Percentage inhibition of the bradycardia responses to vagal stimulation at $10-20 \mathrm{~Hz}$ for $10 \mathrm{~s}$.

A....... Percentage inhibition of the vasopressor responses to carotid occulsion for $10 \mathrm{~s}$.

Vertical lines indicate standard errors.

Impairment of the vagally induced bradycardia occurred at dose levels just below those required to cause neuromuscular paralysis. The vasopressor response to carotid occlusion was reduced appreciably by supramaximal paralysing doses. 

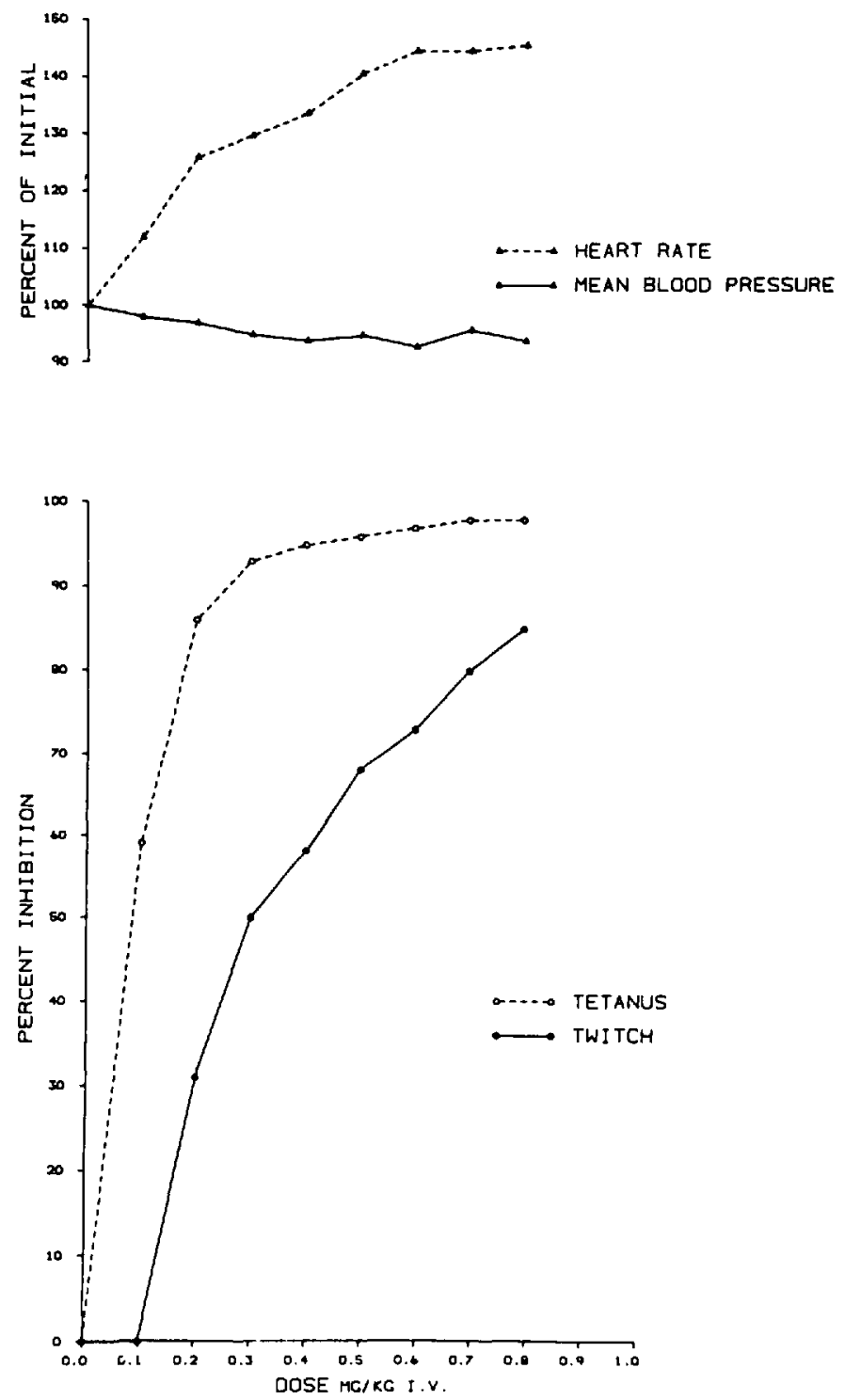

Figune 4. Dose-response curves showing percentage inhibition of indirectly elicited responses of the adductor pollicis muscle to tetanic and single twitch stimulation of the ulnar nerve after intravenous administration of fazadinium bromide in incremental doses of $0.1 \mathrm{mg} / \mathrm{kg}$ to three anaesthetized patients. Maximal changes in heart rate and mean arterial blood pressure were expressed as percentage of initial and the values averaged.

Tetanic contractions of the muscle were more sensitive than single twitches to the neuromuscular paralysing effects of the drug. Changes in mean arterial blood pressure were small but heart rate increased progressively with increasing dosage.

5, Table I). Neuromuscular paralysis of the twitch response was slower in onset, about five minutes, less marked and recovery was slightly more rapid (mean 40 min) than the simultaneously recorded tetanic contractions (Figure 5, Table I). Tachycardia was often appreciable and hypertension was evident in at least three 


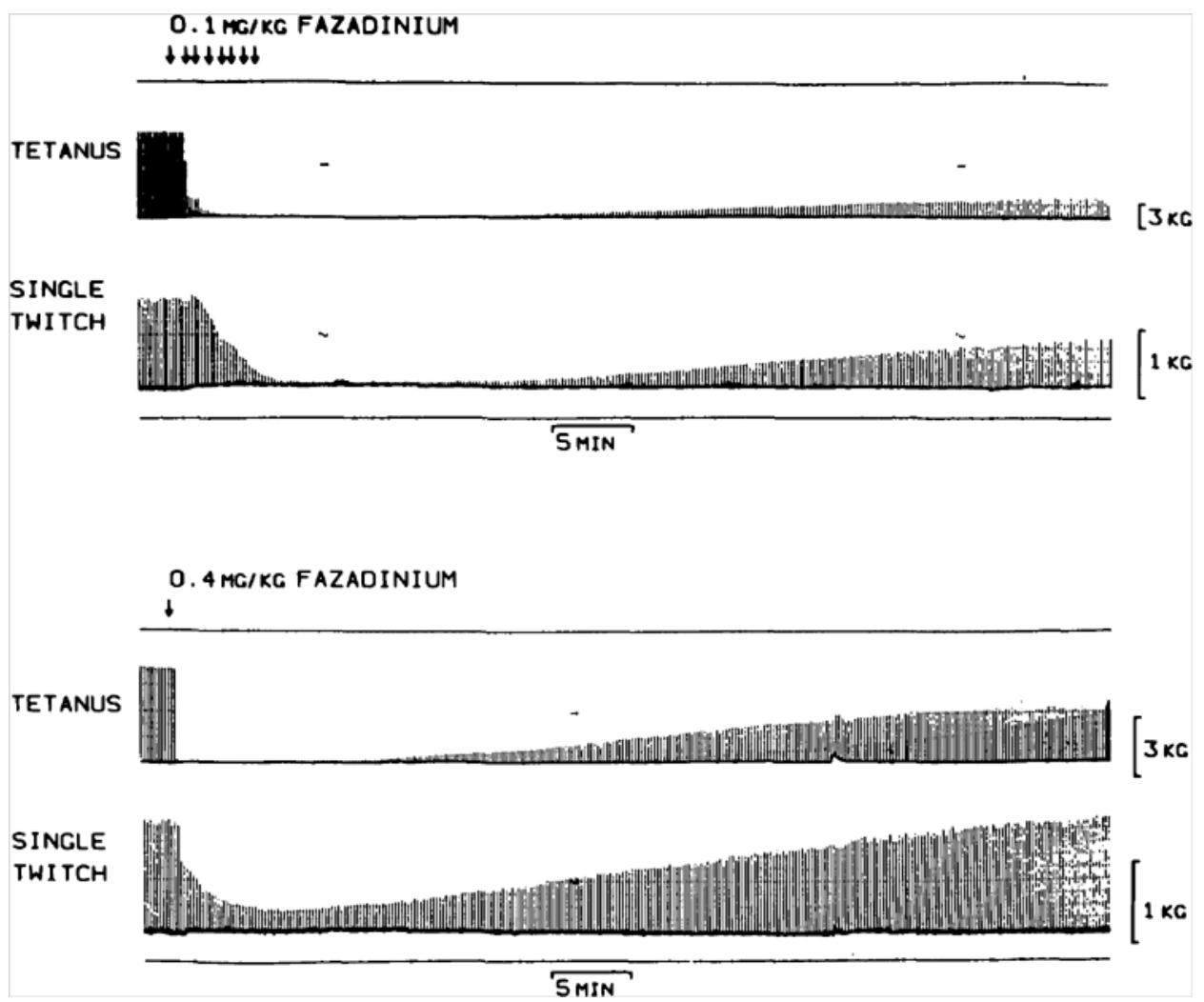

Figure 5. Tracing from two anaesthetized patients (K.H. and C.H.) showing responses of the adductor pollicis muscle to tetanic and single twitch stimulation of the ulnar nerve.

Upper portion: Progressive increase in neuromuscular blockade of both tetanic and twitch responses after eight incremental doses of $0.1 \mathrm{mg} / \mathrm{kg}$ i.v. fazadinium.

Lower portion: Rapid complete block of tetanic contractions by single dose of $0.4 \mathrm{mg} / \mathrm{kg}$ fazadinium - slow recovery ensued with tetanic fade. Blockade of the single twitches was slower in onset, less marked and the subsequent recovery was more rapid than the tetanic responses.

of the patients studied (Table I). In contrast with the pattern of potency, the course of action of fazadinium in man was considerably longer than in cats and comparable with that in rhesus monkeys.

The tetanic-tension ratio was plotted against tetanic transmission both during the onset of neuromuscular blockade by fazadinium and tubocurarine and during the subsequent recovery as shown in Figure 6. Tetanic-tension ratios at 30 and 50 per cent recovery of tetanic transmission were compared with those obtained with tubocurarine. The tetanic-tension ratios with fazadinium were consistently lower than those observed with tubocurarine during both the onset and the recovery phase. Thus, tetanic fade was greater and more persistent after fazadinium than after tubocurarine.

\section{Discussion}

Although fazadinium was introduced as a short acting non-depolarizing neuromuscular blocking agent, in our experience its course of action in cats was longer 
HUGHES, et al.: FAZADINIUM

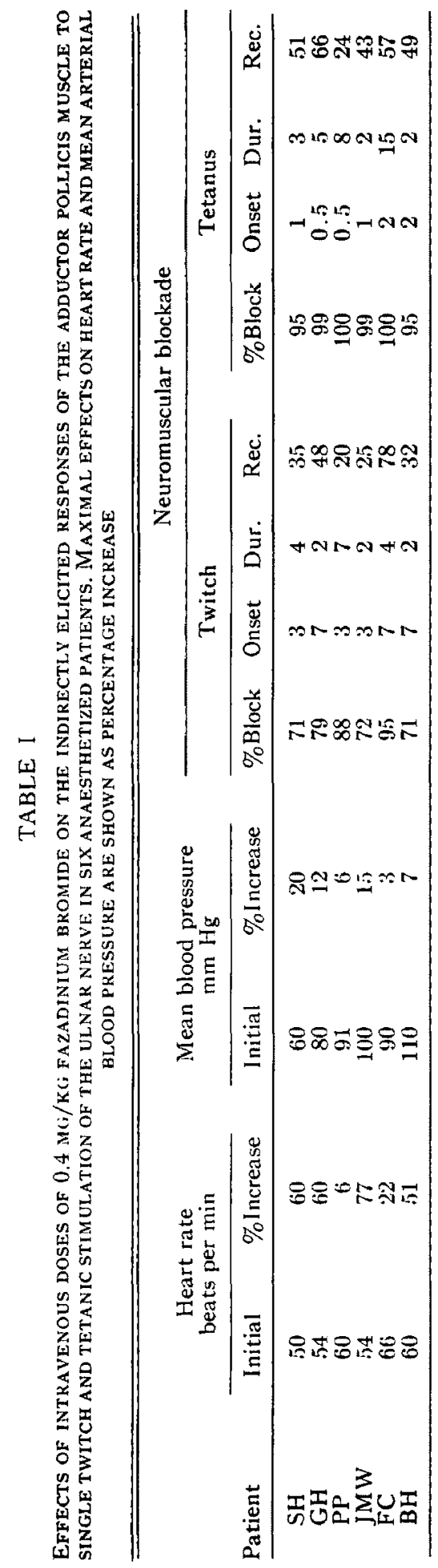



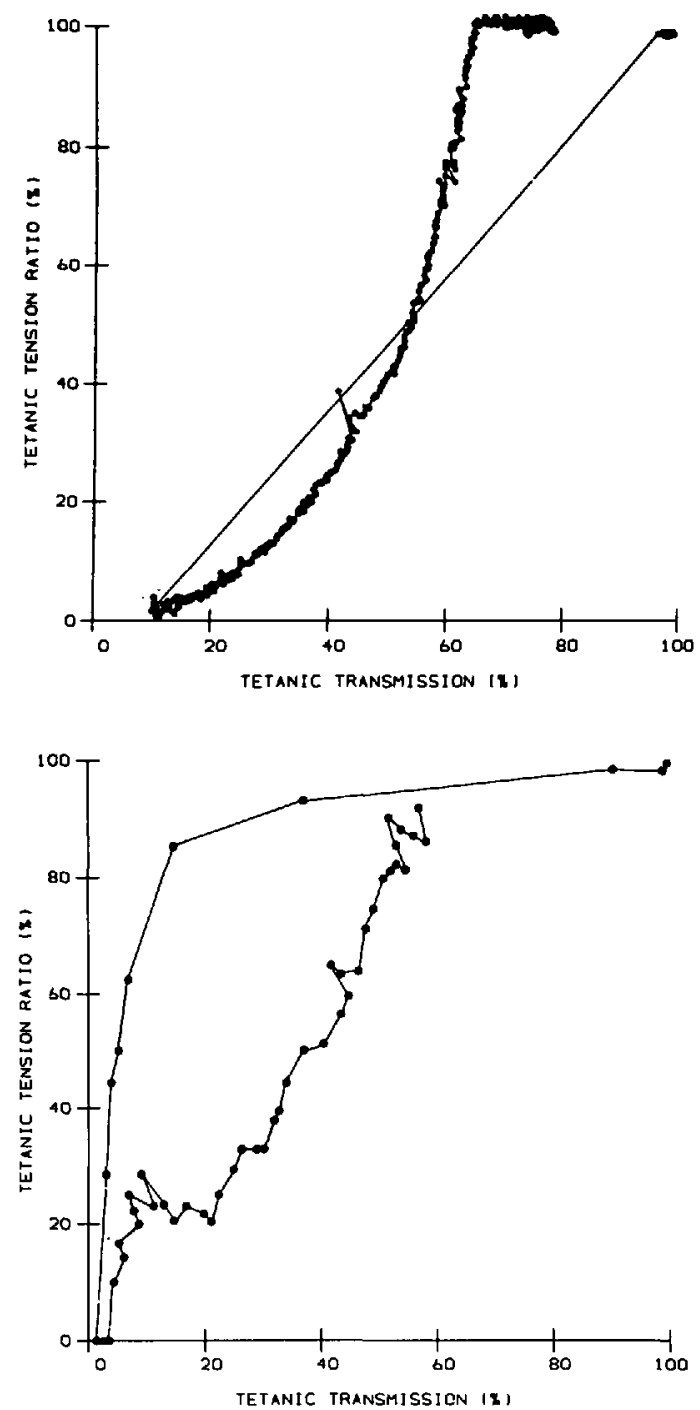

Frgure 6. Tetanic-tension ratios plotted against tetanic transmission during the onset and recovery phases from two patients, one (top) given fazadinium $(0.4 \mathrm{mg} / \mathrm{kg}$ iv) and the other (bottom) tubocurarine $(0.2 \mathrm{mg} / \mathrm{kg}$ iv).

In both patients the control recordings are indicated at the top right of each tracing thereafter the fazadinium tracing falls steeply during onset whereas in the case of tubocurarine the tetanictension ratios are well maintained until tetanic transmission has been reduced to below 20 per cent. The same pattern is seen during the recovery period from the bottom left of each tracing when the ratios at the same level of tetanic transmission are lower with fazadinium than with tubocurarine.

than predicted from earlier work. ${ }^{1}$ It was not appreciably shorter acting than gallamine and, like gallamine, vagal blockade occurred at doses below those required for neuromuscular paralysis. ${ }^{8}$ Unlike gallamine, supramaximal paralysing doses caused sympathetic blockade which was slight in comparison with that produced by tubocurarine. When the investigation was extended to rhesus monkeys 
the neuromuscular paralysing activity was found to be about four times greater than in cats and its course of action was appreciably longer. Effects on autonomic mechanisms were not substantially different from those in cats.

A feature of the dose-response curves in man was the progressive increase in heart rate with increasing dosage. This was perhaps to be expected from the vagal blockade observed in cats and monkeys. A significant increase in heart rate after fazadinium in man has also been reported by earlier workers ${ }^{5}$ and the tachycardia which we observed was of similar magnitude. However, whereas previous reports ${ }^{2,5}$ have indicated that arterial blood pressure was unchanged, we have presented evidence that the drug may cause hypertension in some patients. The fact that in the earlier studies the patients were given halothane ${ }^{2}$ or suxamethonium ${ }^{5}$ may explain the discrepancy.

In relation to the neuromuscular-blocking actions of fazadinium the doseresponse curves obtained from the clinical studies (Figure 4) show that the potency of fazadinium in man corresponds more closely to that in cats than to that in rhesus monkeys. As with other non-depolarising agents, the tetanic contractions were more sensitive than the single twitches to the effects of the drug. Furthermore, the shape of the dose-response curves obtained from inhibition of the single-twitches differed from that derived from the tetanic-contractions (Figure 4). This implies that there are both quantitative and qualitative differences involved in these responses.

After single doses of fazadinium $(0.4 \mathrm{mg} / \mathrm{kg}$ iv $)$, the onset of complete neuromuscular blockade of the tetanic contractions occurred within two minutes of injection but recovery was relatively slow, being of the order of 50 minutes (Figure 5). As opposed to the relative potencies, the duration of action of fazadinium in man was considerably longer than in cats and comparable with that in rhesus monkeys, and in man the drug was only slightly shorter acting than tubocurarine. Depression of the simultaneously recorded single twitches by fazadinium was less marked, slower in onset and recovery was slightly more rapid than the tetanic responses. For complete paralysis of the single-twitch responses at least $0.9 \mathrm{mg} / \mathrm{kg}$ iv was required when given in divided doses. In our studies the paralysing potency of fazadinium in man was less than that reported previously. ${ }^{2}$ This can possibly be explained by the fact that in the earlier studies anaesthesia was maintained with halothane and we have observed that this anaesthetic enhances the neuromuscular blocking action of fazadinium as it does with other non-depolarizing neuromuscular blocking agents. ${ }^{4}$ In our experience the potency of fazadinium is approximately half that of tubocurarine as shown by the fact that a dose of $0.4 \mathrm{mg} / \mathrm{kg}$ fazadinium is needed to obtain the same degree of block produced by $0.2 \mathrm{mg} / \mathrm{kg}$ tubocurarine. Again compared with tubocurarine, the tetanic-tension ratio was substantially smaller after fazadinium and this low ratio persisted longer. The conclusion is that tetanic-tension fade is more pronounced after fazadinium than after a corresponding dose of tubocurarine.

Overall, the findings suggest that fazadinium reaches its active sites at the neuromuscular junction more rapidly than does tubocurarine, but since it is slightly shorter-acting it may be released more quickly. Fazadinium also appears to depress the sustained supply of acetylcholine more readily than does tubocurarine, demonstrated perhaps by the greater fade of tetanic tension when equipotent doses are 
compared. This could mean that if a large or a repeated dose of fazadinium is used a profound neuromuscular block might ensue and clinical experience suggests that this can happen.

\section{SUMMARY}

Intravenous dose-response relationships were used to correlate neuromuscular paralysis with the effects of fazadinium (AH 8165) on autonomic mechanisms in anaesthetized cats and rhesus monkeys and with cardiovascular effects in man. In cats and monkeys neuromuscular paralysis of the twitch responses of the gastrocnemius muscle by fazadinium was accompanied by impairment of the vagally induced bradycardia, but cardiovascular disturbances were small. Blockade of sympathetic mechanisms and hypotension were only evident with supra-maximal doses. In man tachycardia was a common occurrence and in some patients hypertension occurred with doses of the drug needed for complete neuromuscular paralysis.

Fazadinium was three to four times more potent in rhesus monkeys than in cats and its course of action was considerably longer. The potency of the drug in man corresponded more closely to that in cats than in rhesus monkeys but its course of action in patients was similar to that in monkeys.

In man, dose-response curves were constructed for the contractions of the adductor pollicis muscles elicited by tetanic and single twitch stimuli applied to the corresponding ulnar nerves. The onset of paralysis of the tetanic contractions after the intravenous injection of fazadinium $(0.4 \mathrm{mg} / \mathrm{kg})$ occurred within two minutes, but recovery was slow and about 50 minutes were needed for its completion. Depression of the simultaneously recorded twitch responses was less marked, slower in onset and recovery was slightly more rapid. These effects were similar to those obtained with tubocurarine $(0.2 \mathrm{mg} / \mathrm{kg})$ but the action of fazadinium was slightly shorter.

Tetanic-tension ratios were computed after 30 and 50 per cent recovery from neuromuscular blockade in man. These ratios were lower with fazadinium than with tubocurarine and indicated that tetanic fade was greater and more persistent after fazadinium than after tubocurarine.

\section{RÉSUMÉ}

On a administré par voie IV du Fazadinium ( $\mathrm{AH} \mathrm{8165)} \mathrm{au} \mathrm{chat} \mathrm{et} \mathrm{au} \mathrm{singe}$ de type Rhésus afin d'étudier les relations de doses à effet sur les mécanismes autonomes. Cette étude a aussi été faite chez l'homme pour les effets cardiovasculaires du produit.

Chez le chat et le singe, la paralysie du muscle gastrocnemien de la jambe a été accompagnée par une diminution de la bradycardie vaguale. De même on n'a observé que des effets sympathiques minimes alors que chez certains patients les doses nécessaires à l'obtention d'une paralysie neuromusculaire ont entraîné une hypertension artérielle.

On a noté chez le singe une puissance d'action 3 à 4 fois plus grande que chez le chat ainsi qu'une plus longue durée d'action. 
Chez l'homme, la puissance a été comparable à celle du Fazadinium chez le chat et la durée d'action plus longue.

On a pu établir chez l'homme des courbes représentant les relations dose/effet en observant la contraction de l'adducteur du pouce après application de stimuli tétaniques ou isolés aux nerfs correspondants. On a observé une contraction soutenue avec une dose de $0.5 \mathrm{mg} / \mathrm{kg}$ après $40 \mathrm{sec}$. Le retour à la normale s'est fait après 50-60 minutes.

De même on a enregistré simultanément la réponse aux fasciculations. Le temps d'apparition a été plus long, la réponse moins marquée et la durée d'action plus courte. Ces effets sont similaires à ceux obtenus avec $0.2 \mathrm{mg} / \mathrm{kg}$ de DTC.

Le rapport tétanos/tension étudié après 30-50 pour cent de récupération chez l'homme, s'est révélé inférieur avec le Fazadinium comparé à la DTC et l'affaiblissement tétanique (Tetanic fade) plus persistant.

\section{ACKNOWLEDGMENTS}

We are grateful to Mr. D.J. Chapple for help with the animal experiments, to Miss Susan Galloway, S.R.N., and Mr. R. Worsley for technical assistance and to Mr. R. Bartholomew and Mr. A. Sandman for the illustrations. We are also indebted to our nursing and surgical colleagues for their tolerance and patience and to the volunteers for their co-operation.

\section{REFERENCES}

1. Brittain, R.T. \& Tyens, M.B. The pharmacology of AH 8165: a rapid-acting, short-lasting, competitive neuromuscular blocking drug. Brit. J. Anaesth. 45: 837 (1973).

2. Simpson, B.R., Strunin, L., Savece, T.M., Walton, B., Bloge, B., Faley, E.I., Maxwell M.P., Ross, L.A., \& HARris, D.M. An azobis-anylimidazopyridinium derivative: a rapidly acting non-depolarizing muscle relaxant. Lancet 1: 516 (1972).

3. MarshaLL, I.G. The ganglion blocking and vagolytic actions of three short-acting neuromuscular blocking drugs in cats. J. Pharm. Pharmacol. 25: 530 (1973).

4. Hughes, R. Evaluation of the neuromuscular blocking properties and side effects of two new isoquinolinium-bis-quaternary compounds (BW 252C64 and BW 403C65). Brit. J. Anaesth. 44: 27 (1972).

5. Savege, T.M.. Blogg, C.E., Ross, L., Lang, M., \& Simpson, B.R. The cardiovascular effects of AH 8165. A new non-depolarizing muscle relaxant. Anaesthesia 28: 253 (1973).

6. Sugai, N., Hughes, R., \& Payne, J.P. The effect of suxamethonium alone and its interaction with gallamine on indirectly elicited tetanic and single twitch contractions of skeletal muscle in man during anaesthesia. Br. J. Clin. Pharmac, 2: In press (1975).

7. Sugai, N., Hughes, R., \& Payne, J.P. Sequential changes in the fade of tetanic tension after the administration of tubocurarine in man. In Preparation (1975).

8. Hughes, R. \& Chapple, D.J. Effects of non-depolarizing neuromuscular blocking agents on peripheral autonomic mechanisms in cats. Brit. J. Anaesth. In Press (1975). 